\title{
454 Genome Sequencing of Pseudoperonospora cubensis Reveals Effector Proteins with a QXLR Translocation Motif
}

\author{
Miaoying Tian, ${ }^{1}$ Joe Win, ${ }^{2}$ Elizabeth Savory, ${ }^{1}$ Alyssa Burkhardt, ${ }^{3}$ Michael Held, ${ }^{4}$ Federica Brandizzi, ${ }^{4}$ \\ and Brad Day ${ }^{1,3,5}$ \\ ${ }^{1}$ Department of Plant Pathology, Michigan State University, East Lansing, MI 48824, U.S.A.; ${ }^{2}$ The Sainsbury Laboratory, \\ Norwich, NR4 7UH, United Kingdom; and ${ }^{3}$ Graduate Program in Cellular and Molecular Biology, ${ }^{4}$ Department of Energy- \\ Plant Research Laboratory, and ${ }^{5}$ Graduate Program in Genetics, Michigan State University, East Lansing, MI, U.S.A.
}

Submitted 24 August 2010. Accepted 7 January 2011.

\begin{abstract}
Pseudoperonospora cubensis is a biotrophic oomycete pathogen that causes downy mildew of cucurbits, a devastating foliar disease threatening cucurbit production worldwide. We sequenced $P$. cubensis genomic DNA using 454 pyrosequencing and obtained random genomic sequences covering approximately $14 \%$ of the genome, thus providing the first set of useful genomic sequence information for $P$. cubensis. Using bioinformatics approaches, we identified 32 putative RXLR effector proteins. Interestingly, we also identified 29 secreted peptides with high similarity to RXLR effectors at the N-terminal translocation domain, yet containing an $R$-to-Q substitution in the first residue of the translocation motif. Among these, a family of QXLRcontaining proteins, designated as $P c \mathrm{QNE}$, was confirmed to have a functional signal peptide and was further characterized as being localized in the plant nucleus. Internalization of secreted PcQNE into plant cells requires the QXLREER motif. This family has a large number of near-identical copies within the $P$. cubensis genome, is under diversifying selection at the $C$-terminal domain, and is upregulated during infection of plants, all of which are common characteristics of characterized oomycete effectors. Taken together, the data suggest that PcQNE are bona fide effector proteins with a QXLR translocation motif, and QXLR effectors are prevalent in $P$. cubensis. Furthermore, the massive duplication of $P c Q N E$ suggests that they might play pivotal roles in pathogen fitness and pathogenicity.
\end{abstract}

Plant pathogens secrete a diverse array of effector proteins during their interactions with host plants, presumably to facilitate colonization, growth and development on their hosts by suppressing host defense responses (Alfano and Collmer 2004;

Current address for M. Tian: Boyce Thompson Institute for Plant Research, Cornell University, Ithaca, NY 14853, U.S.A.

Current address for M. Held: Ohio University, Department of Chemistry and Biochemistry, Athens 45701, U.S.A.

Corresponding author: B. Day; E-mail: bday@msu.edu

The 454 sequencing data were deposited in the NCBI Short Read Archive database under accession number SRX025566.1. The sequences of $P c \mathrm{QNE}$ (V1 to V6) were deposited in NCBI GenBank under accession numbers HQ108117 through HQ108122.

* The $\boldsymbol{e}$-Xtra logo stands for "electronic extra" and indicates that seven supplementary data files are published online.
Birch et al. 2009). In this sense, all effectors are virulence factors. However, some effectors can be recognized by host resistance $(\mathrm{R})$ proteins and, as a result, initiate specific gene-forgene defense responses (Alfano and Collmer 2004). In such cases, these effectors are termed avirulence (Avr) proteins (Chisholm et al. 2006; Jones and Dangl 2006). In general, based on the targeting or localization site within the host plant, effectors are broadly classified into two classes: apoplastic effectors or cytoplasmic effectors (Kamoun 2006). Whereas apoplastic effectors function in the plant extracellular space, cytoplasmic effectors are delivered inside the plant cell, where they target various subcellular compartments (Hogenhout et al. 2009; Kamoun 2006).

The mechanisms by which cytoplasmic effectors enter host cells are diverse. For example, gram-negative bacteria inject effectors into the cell through a specialized needle-like apparatus, called the type III secretion system (T3SS) (Buttner and He 2009). Similarly, pathogenic nematodes inject effectors inside the cell through a needle-like apparatus called a stylet, which is also used for feeding (Davis et al. 2008). In contrast, neither fungi nor oomycetes appear to have an injection structure similar to the T3SS or the nematode stylet. Thus, the mechanisms of delivery of oomycete and fungi effectors remain to be fully characterized. Many characterized effector proteins from fungi and oomycetes contain an endoplasmic reticulum (ER)-type signal peptide recognized by a type II secretion system (T2SS) (Dodds et al. 2009), suggesting that these proteins are secreted from the pathogen cells. How these secreted proteins cross the host plasma membrane and enter the host cell had been a mystery until the identification of an ArgX-Leu-Arg (RXLR) translocation motif, which was identified based on its presence and conservation across all characterized Avr proteins of oomycetes (Morgan and Kamoun 2007). This motif is interchangeable with the host-targeting signal (HTS) or PEXEL motif from Plasmodium falciparum (Bhattacharjee et al. 2006; Grouffaud et al. 2008). The RXLR motif, together with its downstream Asp-Glu-Glu-Arg (dEER) motif, which is less conserved and comprises a stretch of acidic amino acids often ending with EER (Birch et al. 2008), was shown to be required for host cell entry for the Phytophthora infestans effector Avr3a (Whisson et al. 2007) as well as the P. sojae effector Avr1b (Dou et al. 2008). Interestingly, Avr1b was found to be able to enter the cell in the absence of the pathogen (Dou et al. 2008), suggesting a host-mediated translocation process. A further study published very recently shows that the RXLR motif and its variants in both oomycetes and fungi enable the 
effectors to bind phosphatidylinoditol-3-phosphate (PI3P) on the outer surface of plant and human cell plasma membranes, and this binding mediates the effector entry through lipid raftmediated endocytosis (Kale et al. 2010). Although the detailed translocation process remains to be fully defined, this study suggests a general cell entry mechanism for cytoplasmic effectors from oomycetes and fungi.

With the completion of numerous genome sequences from a broad spectrum of plant and mammalian pathogens, bioinformatics approaches have enabled genome-wide identification of effector proteins (Arnold et al. 2009; Jiang et al. 2008; Samudrala et al. 2009; Whisson et al. 2007). These computational methods are typically developed through the identification of shared characteristics of known, characterized effector gene or protein sequences. For example, a machine-learning approach was developed for the prediction of type III secretion system effector proteins by systematically analyzing the amino acid composition and secondary structure of $\mathrm{N}$ termini of 100 experimentally determined effector proteins (Arnold et al. 2009). Similarly, the large-scale identification of oomycete effectors has been facilitated by computational searches for an ER-type signal peptide, followed by a downstream RXLR translocation motif and, usually, a stretch of acidic amino acids ending with an EER motif (Jiang et al. 2008; Whisson et al. 2007; Win et al. 2007). To this end, hundreds of putative effector proteins have been bioinformatically predicted to reside within each genome of the sequenced Phytophthora spp. (Jiang et al. 2008; Whisson et al. 2007). The identification of large repertoires of RXLR effectors provides limitless opportunities to determine how oomycetes manipulate their hosts to suppress defense responses and establish successful infection.

Pseudoperonospora cubensis is a biotrophic oomycete pathogen responsible for downy mildew of cucurbits, a devastating foliar disease worldwide (Savory et al. 2010). This disease is notorious for its fast development and, as such, infected cucumber leaves can become frosted within 10 days of initial infection. Since 2004, cucurbit downy mildew has become an increasing concern for cucumber growers in the United States due to the emergence of new virulence within $P$. cubensis populations (Holmes et al. 2006). As a result of this increased virulence, previous downy mildew resistance, which has been bred into most of the popular cultivars in use today, has failed, leaving growers with few options to manage the disease (Holmes et al. 2006). Although the genomes of many plant pathogens have been sequenced, genomic resources for $P$. cubensis are nonexistent.

In this study, we sequenced $P$. cubensis genomic DNA using 454 pyrosequencing technology and obtained random genomic sequences covering approximately $14 \%$ of the genome. An initial search for putative RXLR effectors using the Basic Alignment Analysis Search Tool (BLAST) against RXLR effector proteins from Hyaloperonospora arabidopsidis and Phytophthora infestans identified not only RXLR-EER-containing sequences but also sequences with variations of the conserved RXLR, including Lys-X-Leu-Arg (KXLR) and Gln-X-LeuArg (QXLR). Interestingly, more QXLR-containing sequences were identified than RXLR- and KXLR-containing sequences. This led us to modify RXLR to QXLR strings in the RXLR effector identification pipeline (Win et al. 2007) and identify secreted RXLR-like QXLR-containing proteins. In all, 29 such sequences were found, suggesting that QXLR-containing sequences are highly represented, compared with 32 RXLR-containing sequences found in this data set. In completing and resequencing a number of QXLR-containing sequences, we identified a gene family encoding secreted and nuclear-localized proteins, with massive multiplication in the genome. We named proteins encoded by this gene family Pseudoperono- spora cubensis QXLR nuclear-localized effectors (PcQNE). Variants of $P c \mathrm{QNE}$ induced chlorosis and necrosis on Nicotiana benthamiana, were under diversifying selection, and were upregulated during infection of plants. Internalization of secreted $P c$ QNE into plant cells requires the QXLR-EER motif. Together, we conclude that $P c \mathrm{QNE}$ is a novel family of effector proteins with a functional QXLR translocation motif.

\section{RESULTS}

Generation of random genomic sequences of $\boldsymbol{P}$. cubensis.

We performed two runs of 454 pyrosequencing with genomic DNA isolated from P. cubensis sporangia. In total, 605,921 reads containing 135.4 million nucleotides (nt) were generated. After removing identifiable cucumber sequence, 588,461 reads containing 131.1 million nt remained. The data were assembled using the Roche gsAssembler (version 1.1.03), and $87.8 \%$ of the reads, representing $62.9 \%$ of the nucleotides, were fully or partially assembled. In total, 42,799 contigs were generated with a total length of 12.1 million $\mathrm{nt}$, accounting for approximately one-seventh (approximately 14\%) of the genome, assuming that the genome size of $P$. cubensis is $88.22 \mathrm{Mb}$, as predicted by Feulgen image analysis (Voglmayr and Greilhuber 1998). Among them, there were 3,413 large ( $\geq 500 \mathrm{nt}$ ) contigs, with a total length of 2.94 million nt and an average length of $863 \mathrm{nt}$. The longest contig was composed of 9,219 nt. The 454 sequencing data were deposited in the National Center for Biotechnology Information (NCBI) Short Read Archive under accession number SRX025566.1. The sequences of 3,413 large contigs are provided in Supplementary Data 1.

\section{Identification of putative RXLR effector proteins.}

To identify potential effector proteins, the 3,413 large sequence contigs were analyzed using the RXLR effector identification pipeline (Win et al. 2007). In total, 12,131 peptides were translated from both strands. Among the 604 predicted secreted peptides, 32 nonredundant peptides (Supplementary Data 2) were found to contain an RXLR motif located downstream of the signal peptide and in position between 30 and 60 amino acids starting from the $\mathrm{N}$ terminus of the protein, a common feature of identified oomycete RXLR effector proteins (Win et al. 2007). We also analyzed the sequences of the 604 putative secreted peptides using a Hidden Markov Model (HMM) from an alignment of the RXLR-dEER region generated with 43 validated oomycete RXLR effector proteins (Win et al. 2007). Five sequences, which were also identified using the RXLR effector identification pipeline, were found to contain both the RXLR and EER motif.

\section{Discovery of a set of RXLR effector-like proteins with a QXLR motif.}

In searching for putative RXLR effector proteins, we also performed bidirectional BLAST sequence similarity analyses using the 3,413 large contigs from $P$. cubensis, 149 putative RXLR effectors from $H$. arabidopsidis (Win et al. 2007), and 563 RXLR effector proteins from Phytophthora infestans (Haas et al. 2009). From this, a number of peptide sequences from Pseudoperonospora cubensis were found to align with effectors from $H$. arabidopsidis or Phytophthora infestans at the N-terminal RXLR-dEER regions (data not shown). Additional in silico analysis was performed to determine whether these sequences contained a putative signal peptide or an RXLR or conserved EER motif. Interestingly, we not only identified sequences encoding putative RXLR effector proteins but also sequences encoding QXLR- and KXLR-containing secreted peptides. Surprisingly, we identified more QXLR- than RXLRcontaining sequences in this screen. Among 11 sequences identi- 
fied by an initial BLAST search, six encoded QXLR-containing secreted peptides. These QXLR peptides exhibited high similarity with RXLR effectors at the N-terminal region, including a predicted signal peptide and a downstream conserved QXLRdEER domain with a position similar to the RXLR-dEER translocation motif of RXLR effectors (Fig. 1). The high percentage of representation and resemblance with RXLR effectors led us to consider that the QXLR tribe likely represented a class of effector proteins with a unique translocation motif. To increase the breadth of our bioinformatics analyses, we modified the RXLR effector identification pipeline to identify additional QXLR-containing secreted proteins. In total, 29 sequences (Supplementary Data 3) were identified using 3,413 large contigs running through the QXLR effector identification pipeline. Compared with 32 putative RXLR effectors identified in this data set, QXLR effectors seem to be prevalent in Pseudoperonospora cubensis. Interestingly, scanning of complete genome sequences of Phytophthora infestans and $H$. arabidopsidis revealed only 11 and eight putative effector proteins, respectively, with apparent QXLR motif (Supplementary Data 4), two of which, from $P$. infestans, contain overlapping QXLR-RXLR motif, suggesting adaptation and conservation within Pseudoperonospora cubensis.

\section{Sanger resequencing identified a putative secreted nuclear-localized QXLR-EER effector.}

To confirm that the substitution of $\mathrm{R}$ within the RXLR motif by $\mathrm{Q}$ was not the result of misreads generated by 454 pyrosequencing, we chose three QXLR-EER sequences, encoded by nucleotide sequences from contig40202, contig35787, and contig35796 (Fig. 1), for resequencing by the dideoxy chain termination Sanger sequencing approach. In all three cases, the substitution of $\mathrm{R}$ to $\mathrm{Q}$ was confirmed (data not shown), suggesting the presence of QXLR-EER-containing secreted proteins within the $P$. cubensis genome. We also did $3^{\prime}$ rapid amplification of cDNA ends (RACE) polymerase chain reaction (PCR) to obtain the complete protein-encoding sequences. For the QXLR-EER sequence from contig40202, we sequenced one clone derived from the $3^{\prime}$ RACE-PCR product cloned into pCR2.1 TOPO vector. After assembling with the sequence generated from 454 sequencing, we identified an open reading frame (ORF) with a putative nuclear localization signal (NLS) predicted by PredictNLS. For convenience, we named the gene $P$. cubensis QXLR nuclear-localized effector (PcQNE). We then designed a pair of primers to amplify the whole ORF from sporangia cDNA and cloned the resultant products into the vector pCR2.1 TOPO. Initially, we sequenced six clones.

ATR1 NdWsB
Avr3a
Avr1b-1
contig40202
Contig35787
Contig35796

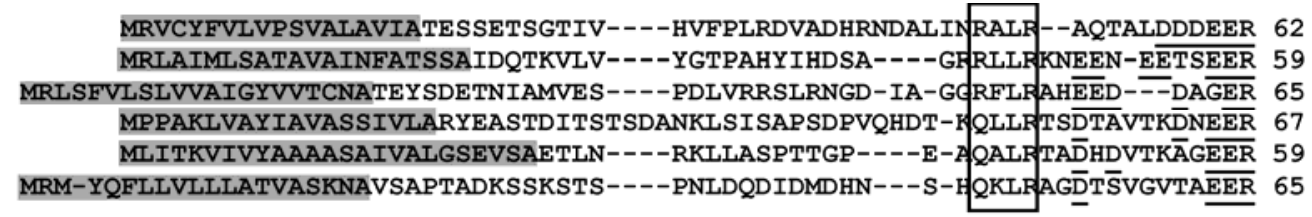

Fig. 1. Alignments of N-terminal regions of three characterized RXLR effector proteins from Hyaloperonospora arabidopsidis $\left(\mathrm{ATR} 1^{\mathrm{NdW} B}\right)\left(\mathrm{Rehmany}_{\mathrm{e}}\right.$ et al. 2005), Phytophthora infestans (Avr3a) (Armstrong et al. 2005), and P. sojae (Avr1b-1) (Shan et al. 2004), with three representative QXLR-containing secreted peptides derived from contig40202, contig35787, and contig35796, respectively. The signal peptides predicted by SignalP 3.0 are shaded in gray. The conserved Q/RXLR motif is shown in the box. The acidic amino acids together with the ending EER sequence in the dEER motif are underlined.
SP

v2 MPPAKLVAYIAVASSIVLARYEASTDI TSTSDANKLSISAPSDPVOHDTKOLLRTSDTAVTKDNEERMFNAAGLKRASTMSHFADVHGLPHE PLAPHLHDTYDPAGASRPPVLPY TGEA 120

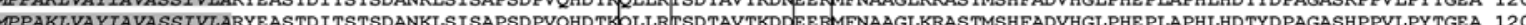
MPPAKLVAYTAVASSIVLARYEASTDITSTSDANKLSISAPSD PVOHDTKOLRTSDTVTKDDE MPPAKLAAYFAVASSIVLARSEASSDI TDTNDTNKLSISAPSDPVQHDTKQPLRTSDTAVTKANEERMFNVAGLRRGSTMSHLPDVHGLPHE PLAPHLHDTYDPAGAPHPPVLPY TDEA 120 MPPAKLVAYIAVASSIVLARYEASTDI TSTSDANKLSISAPSDPVQHDTKQLLRTSDTAVTKDNEERMFNAAGLKRASTMSHFADVHGLPHEPLAPHLHDTYDPAGASHPPVLPY TGEA 120

NLS

V1 KAHEDLQHAASTSNPLKKISPADTQLTEEENSEAEMLKE IMTLIHPAAPE TLKRKR--PEGTE IQFRWKESE I INLY TKHMDQFLS IMNEWWLSNIGPYKFKGRI TQNHLPIRISNAYGN 238 V2 KAHEDIHAASTSNPLKKISPADTOL V2 KAHED V3 KAHEDLQHAASTSNPLKKISPADTQLTEGEDSEAEMLKE IMTPIQPAAPE TLKRKR-PEGTEIQFQWNESEIVNLYTKHKDQFLSIMNECWLSSIGPQDFNRRITDNKLPERIAVRYSR 238 V4 KA V5 KAHWDLQHAAT V6 KAHEDLQHAASTPNPLKKISPADTQLTEGENSEAEMLKE IMTLIQPAAPE TLKRKR--PEETE IQFQWNESEI INLYTKHKDQFLSIMNECWLSNIGPYKFKGRI TQNHLPIRISNAYGN 238

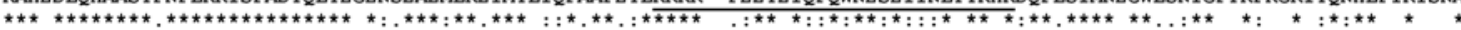

V1 FHAAKNNEVYKHFLDWHNDNIPPRE IDNE INAVLPEARKEALVARFMDDYKEFYEKERKHE TDRMKLLAEDTE PEEAERLKSKKWDRLRVVLKVRSSQRKTKFTLQWFRKHPNEFLLKSI 358 V2 LHAAKNNEVYEHFLDWHNDNILPRE IENE INAVLPEARKEALVARFKKEYE KFYEDEKKHE TDRMKLLAEDTE PEEAKRLKTEKWNRLRLVLNRRIPKRI TKY TOQWYOEHPNE FLLKSM 35 V3 LHAAKNNEVYEHFLDWHNDNILPRE IENE INAVLPEAAKEALVARFKKEYEKFYEDEKKHE TDRMKLLAEDTEPEEAKRLKTEKWNRLRLVLNRRIPKRI TKYTOOWYOEHPNE FLIKSM 35 V4 FHAAKDEEMYEHFAKWONEGILPKEIIEKINAVLPKARKAPLVVRLENKYEVFYKKKOPFEAYRTKLLDEDTEPEEAERLKSKKWDRLRVVLKVRSSORKTKFTLOWFRKHPNEFLLKSI 35 V5 LHAKNNEVYEHFLDWHNDNIPPREIDNE INAVLPEARKEALVARPMDYKE FYEKERKHETDRML 6 FHAAKNNEVYKHFLDWHNDNIPPRE IDNE INAVLPEARKE ALVARFKKEYEKFYEDEKKHE TDRMKLLAEDTEPEEAKRLKTEKWNRLRLVLNRRIPKRITKYT TQQWYQEHPNE FLLKSM 358

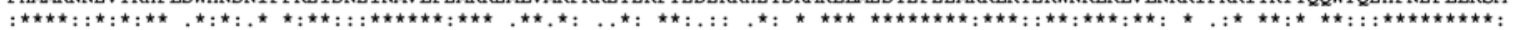

V1 QEGTPPEDIRSVLGLARLEGLKLFKHPNYEYYLKYLKLWFQTHSTEHWQERVPKGMPPEDVRFILGLGQLKGSEFSQHPNFPEYIKFFELWHEAYTRKKMKEWMQLNTPLDEAFAKLAIR 478 V2 QEGTPPEDIRRVLGLAQLKGIRLFKHPNYEYYLRYLKSWFE THPTEHWQERVPKGMPPKDVRFILGLGQLKGSEFSQHPNFPEYIKFFALWHEAY TRKKMKEWMQLNTPLDEAFAKIAIR 478 V3 QEGTPPEDIRRVLGLAQLKGIRLFKHPNYEYYLRYLKSWFE THPTEHWQERVPKGMPPKDVRFILGLGQLKGSEFSQHPNFPEYIKFFELWHEAYTRRKMKEWMQLKTPPDEVFAKIAAVR 478 V4 QEGTPPEDIRSVLGLARLEGLKLFKHPNYEYYLKYLKLWFQTHSTEHWQERVPKGMPPEDVRFILGLGQLKGSEFSQHPNFPEY IKFFELWHEAYTRKKMKEWMQLNTPLDEAFAKLAIR 480 V5 QEGTPPEEVRRVLGLAQLKGIRLFKHPNYEYYLRYLKSWFE THPTEHWQERVPKGMPPEDVRFILGLGQLKGSELSQHPNFPEY IKFFALWHEAY TRKKMKEWMQLNTPPDEVFAKLAIR 478 V6 QEGTPPEDIRRVLGLARLEGLKLFKHPNYEYYLKYLKLWFOTHSTEHWOERVPKGMPPEDVRFILGLGOLKGSEFSOHPNFPEYIKFFELWHEAYTRKKMKEWMOLNTPLDEAFAKI AIR 478

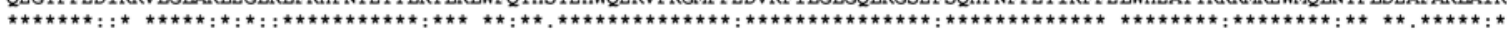

V1 DHNDVEFIVDKSDLYMKOYENEWKKKHPTLRTPAVST 515

V2 DHNDVEFIVDKSDLYMKOYENKWKKKHPTI

V3 DHDDVEYIPDKSDVYIKEYENEWKKKHPTLRTPAVST 515

V4 DHNDVEFIVDKSDLYMKQYENEWKKKHPTLRTPAVST 517

V5 DHNDVEFIVDKSDVYMKQYENKWKKKHPTL------ 50

V6 DHNDVEFIVDKSDLYMKQYENEWKKKHPTL------- 508

${ }^{* *}: * * *: * * * * *: *:^{*}: * * *: * * * * * * * *$

Fig. 2. Multiple alignments of amino acid sequences of six variants of $P c$ QNE. The signal peptides predicted by SignalP 3.0 are shown in italic and shaded in gray. QXLR and EER motifs are in the box. The putative nuclear localization signals (NLS) predicted by PredictNLS are underlined. 
Interestingly, all the sequences are highly related but different from each other, and were designated as V1 through V6. Whereas V1 and V3 encode a protein of 515 amino acids, V4 is 2 amino acids longer due to a 6-nt insertion in the gene, and V2, V5, and V6 are 7 amino acids shorter due to an earlier stop codon generated from a single nucleotide substitution. They all have a putative signal peptide predicted by SignalP 3.0 and QXLR that is downstream of the signal peptide cleavage sites, located between 51 and 56 amino acids, and followed by EER sequence (Fig. 2). This is consistent with identified RXLR effectors (Win et al. 2007) except the R-to-Q substitution in the translocation motif. All variants, except V1, have a putative NLS (Fig. 2).
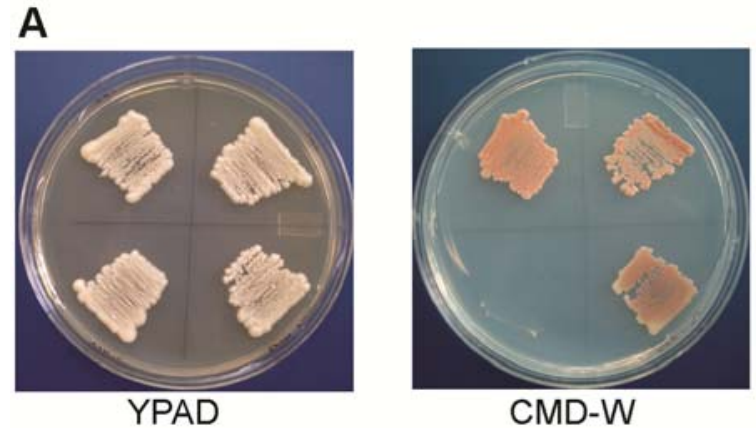

CMD-W

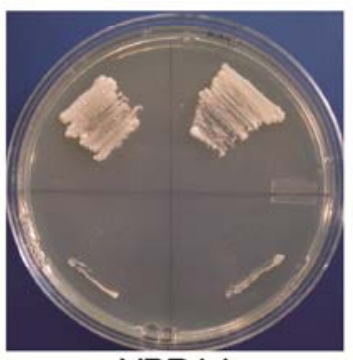

YPRAA

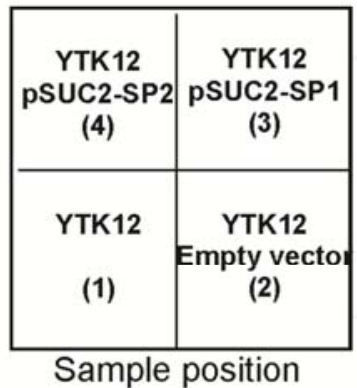

B

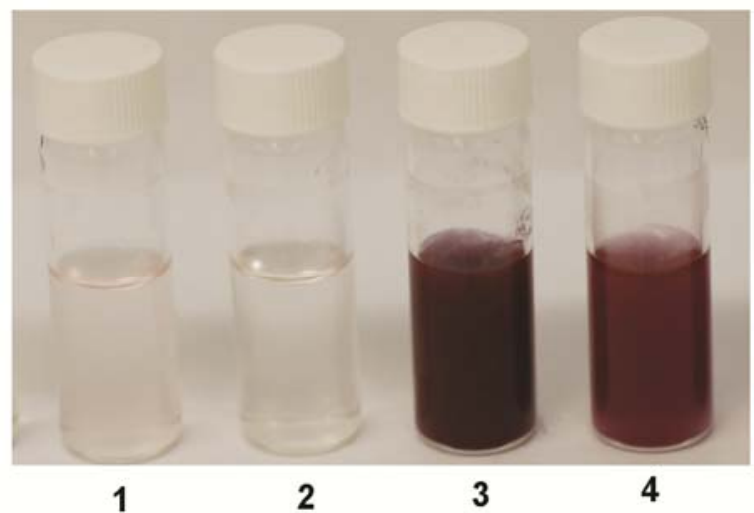

Fig. 3. Functional validation of the signal peptides of $P c \mathrm{QNE}$ proteins using the yeast invertase secretion assay. A, Yeast growth assay on media with (yeast-peptone-glucose-adenine hemisulfate agar [YPAD] and CMD$\mathrm{W}$ ) or without (yeast-peptone-raffinose-Antimycin A agar [YPRAA]) glucose. Yeast YTK12 strains carrying pSUC2-SP1 (3) and pSUC2-SP2 (4), which express two different signal peptide fragments fused in frame to the mature invertase gene SUC2, are able to grow in YPRAA media with raffinose as a sole carbon source. YTK12 (1) and the YTK12 strain carrying empty vector pSUC2T7M13ORI (2) do not secrete invertase and, thus, are not able to grow on YPRAA media. Yeast growth on YPAD and CMD-W serves as an equal viability and strain integrity controls. B, Detection of the secreted invertase activity with 2,3,5-triphenyltetrazolium chloride (TTC). The red color indicates invertase activity. The numbers are used for labeling reactions derived from various yeast strains shown in A.
Functional validation of signal peptides of PcQNE variants.

The six variants encode two distinct versions of putative signal peptides (Fig. 2). V1, V2, V3, V4, and V6 share the same signal peptide sequence, named SP1. The signal peptide from V5 is unique and was designated SP2. A genetic assay based on the requirement of invertase secretion for yeast growth on media with sucrose or raffinose as the sole carbon source was previously used for identifying secreted proteins from human peripheral blood mononuclear cells (Jacobs et al. 1997). More recently, this assay was used to validate in silico signal peptide predictions for Phytophthora infestans RXLR effector proteins (Oh et al. 2009). To test whether SP1 and SP2 were functional, we fused the predicted signal peptides SP1 and SP2 (Fig. 2) in-frame with the mature sequence of yeast invertase SUC2 in the yeast signal sequence trap vector pSUC2T7M13ORI, and the resultant constructs were transferred into a yeast SUC2minus strain, YTK12. YTK12 and YTK12 expressing the SUC2 mature sequence did not grow on raffinose-containing yeast-peptone-raffinose-Antimycin A agar (YPRAA) medium (Fig. 3A); however, the fusion of SP1 and SP2 to the SUC2 mature sequence enabled the successful secretion of invertase, thus enabling the yeast cells to hydrolyze raffinose and grow on YPRAA media. The secretion of invertase and the hydrolysis of raffinose into monosaccharides were also confirmed with 2,3,5-triphenyltetrazolium chloride (TTC), which reacts with monosaccharides to form the insoluble (red colored) triphenylformazan (Fig. 3B). In total, these results suggest that $P c \mathrm{QNE}$ proteins are secreted from Pseudoperonospora cubensis.

Variants of $P c Q N E$ are localized within the plant nucleus.

To confirm the in silico prediction of nuclear localization and to gain insight into the possible function of the $P c \mathrm{QNE}$ effectors, the subcellular localization of $P c \mathrm{QNE}$ variants was determined by transiently expressing DsRed- $P c \mathrm{QNE}$ fusion proteins in $N$. benthamiana using Agrobacterium tumefaciensmediated transformation. With the exception of variant V1, all five members have a predicted NLS (Fig. 2). Based on this, we chose variants V1 and V6 for subcellular localization by laser confocal microscopy. The sequences encoding mature proteins of V1 and V6 were fused to the C-terminus of DsRed, and coexpressed with the green fluorescent protein (GFP)-tagged Arabidopsis fibrillarin protein AtFib1, a nucleolar marker (Goodin et al. 2002). In contrast to DsRed alone, both DsRedV1 and DsRed-V6 were localized in focal spots overlapping and surrounding the GFP-marked nucleoli (Fig. 4), suggesting that both V1 and V6 are localized in the nucleus.

\section{Internalization of secreted $P c \mathrm{QNE}$ requires QLLR-EER motif.}

To determine whether the QXLR-EER motif plays a role in translocating effectors inside the host cell, we undertook an internalization analysis of secreted proteins in the absence of the pathogen, as described by Rafiqi and associates (2010). We used site-directed mutagenesis to make alanine (A) substitutions in the QLLR or EER motif of PcQNE_V1 and generated C-terminal CFP fusion expression constructs (Fig. 5), which were expressed and visualized in $N$. benthamiana. Although wild-type V1 possessed a functional signal peptide, it was localized in the nucleus (Fig. 5A), suggesting that V1 can be successfully internalized after being secreted. Mutation of EER to AAA resulted in both nuclear localization and weak fluorescence accumulation in the apoplast of $N$. benthamiana cells (Fig. 5C), suggesting that EER is involved in cell entry. Although substitution of QLLR alone with AAAA did not seem to compromise the protein internalization (Fig. 5B), altering both QLLR and EER with Ala residues almost completely 
blocked cell entry, as evidenced by the strong fluorescence accumulation in the apoplast and no fluorescence observed in the nucleus (Fig. 5D). Altogether, the data suggested that both QLLR and EER function in V1 internalization after being secreted into the apoplast, implying the role of QXLR-EER motif in effector translocation during pathogen infection.

\section{$P c \mathrm{QNE}$ variants induce chlorosis and necrosis on $N$. benthamiana.}

A. tumefaciens transient expression in $N$. benthamiana is a rapid, informative method to gain insight into the possible mechanism of effector activity and action (Oh et al. 2009). The Agrobacterium strains expressing DsRed alone and DsRed-V1 or DsRed-V6 fusion constructs were infiltrated into leaves of $N$. benthamiana and the phenotypes were monitored. Leaf areas expressing DsRed-V1 started to show chlorosis at 3 days postinoculation (dpi) and weak necrosis appeared as early as 4 dpi (Fig. 6). DsRed-V6 showed similar chlorosis phenotypes, lagging DsRed-V1 by 1 to 2 days (Fig. 6). The cell death responses induced by DsRed-V1 increased following 4 dpi and, by $6 \mathrm{dpi}$, the infiltrated tissue was completely dehydrated and necrotic. In contrast, the chlorosis induced by DsRed-V6 did not change much (i.e., at $6 \mathrm{dpi}$ ) compared with the phenotype at 4 dpi (Fig. 6). Infiltration of $N$. benthamiana leaves with the DsRed showed no chlorosis or necrotic lesions.

\section{$P c Q N E$ variants belong to a large gene family.}

The identification of six nonredundant sequences among the initially sequenced clones led us to hypothesize that $P c Q N E$ variants belong to a large multigene family. Based on this hypothesis, we sequenced an additional $56 \mathrm{cDNA}$ clones isolated in our original cloning of $P c Q N E$. In total, $62 P c Q N E$ clones were sequenced. From this, we determined that 47 highly related yet divergent sequences with at least one nonsynonymous nucleotide change were present (Supplementary Data 5). Among the 47 variants, 39 were represented as single copies, whereas the remaining eight variants were present in approximately two to four copies. Although proofreading Pfu Turbo DNA polymerase (Stratagene) was used for amplification to minimize changes through PCR, it is possible that some variants were simply mutated PCR products. Following the method described by Cline and associates (1996), the percentage of mutated PCR products was calculated as $6.8 \%$ based on the error rate $\left(1.3 \times 10^{-6}\right)$ of $P f u$ Turbo DNA polymerase, the length (approximately $1.5 \mathrm{~Kb}$ ) of $P c Q N E$ genes, and number of template doublings (35, assuming all PCR cycles are effective in amplification). As a result, four to five of $62 P c Q N E$ clones could contain mutations generated through PCR error. Nevertheless, there were still 42 divergent sequences present in the $P$. cubensis genome, suggesting that $P c Q N E$ variants belong to a large gene family.

\section{The PcQNE family is under diversifying selection.}

To identify the selection pressure driving sequence diversification in the PcQNE family, we calculated the rates of nonsynonymous $\left(d_{\mathrm{N}}\right)$ and synonymous $\left(d_{\mathrm{S}}\right)$ changes across the entire ORF of the 47 sequences. In all, $84 \%(909 / 1,081)$ pairwise comparisons were found to have greater $d_{\mathrm{N}}$ than $d_{\mathrm{S}}\left(\omega=d_{\mathrm{N}} / d_{\mathrm{S}}>1\right)$
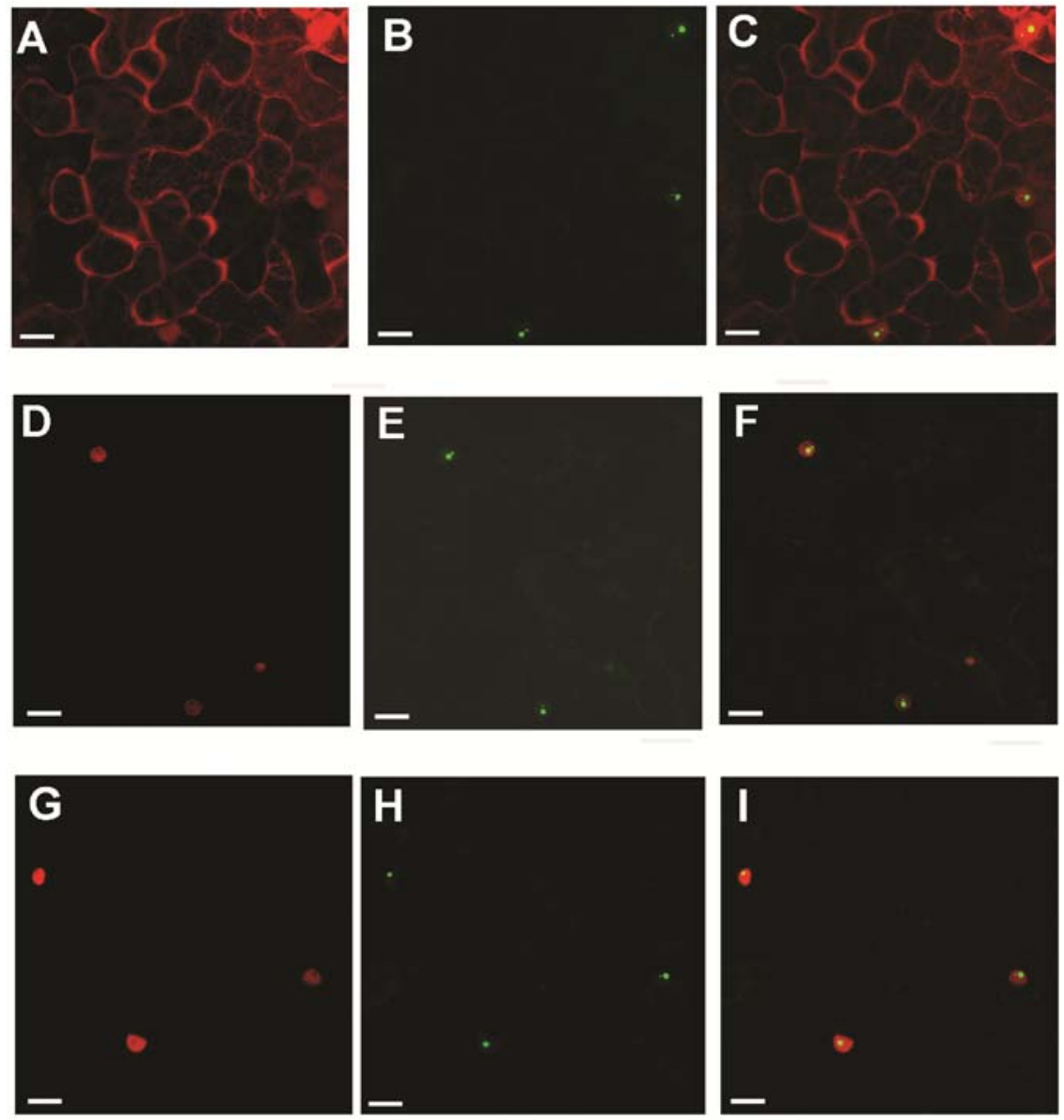

Fig. 4. Laser-scanning confocal micrographs showing fluorescence of leaf cells coexpressing A, B, and $\mathbf{C}$, DsRed and AtFib1-green fluorescent protein (GFP); D, E, and F, DsRed-V1 and AtFib1-GFP; or G, H, and I, DeRed-V6 and AtFib1-GFP by transient agroinfiltration in Nicotiana benthamiana. The red channel shows localization of A, DsRed alone; D, DsRed-V1; or G, DsRed-V6. The green channel shows localization of B, E, and H, AtFib1-GFP. Overlays of micrographs from A and B, D and E, and G and H, are shown in C, F, and I, respectively. Bars $=20 \mu \mathrm{m}$. 
(Fig. 7A; Supplementary Data 6), suggesting that the PcQNE family is experiencing active diversifying selection. Win and associates (2007) showed that positive selection usually targets to the C-terminal domain of oomycete effectors. To determine whether this is applicable to the PcQNE family, we partitioned the sequences into $\mathrm{N}$-terminal regions (from the start codon to QXLR-EER sequences) and C-terminal regions. For the C-terminal regions, we found that $d_{\mathrm{N}}$ was greater than $d_{\mathrm{S}}$ in approxi- mately $90.2 \%(975 / 1,081)$ of comparisons (Fig. 7B). In sharp contrast, only $20.6 \%(223 / 1,081)$ of comparisons gave higher $d_{\mathrm{N}}$ than $d_{\mathrm{S}}$ in the N-terminal regions (Fig. 7C).

\section{The PcQNE family is upregulated upon infection.}

We used quantitative reverse-transcription (RT)-PCR to examine the expression of $P c Q N E$ genes during infection of cucumber by $P$. cubensis. Although the primers used were designed
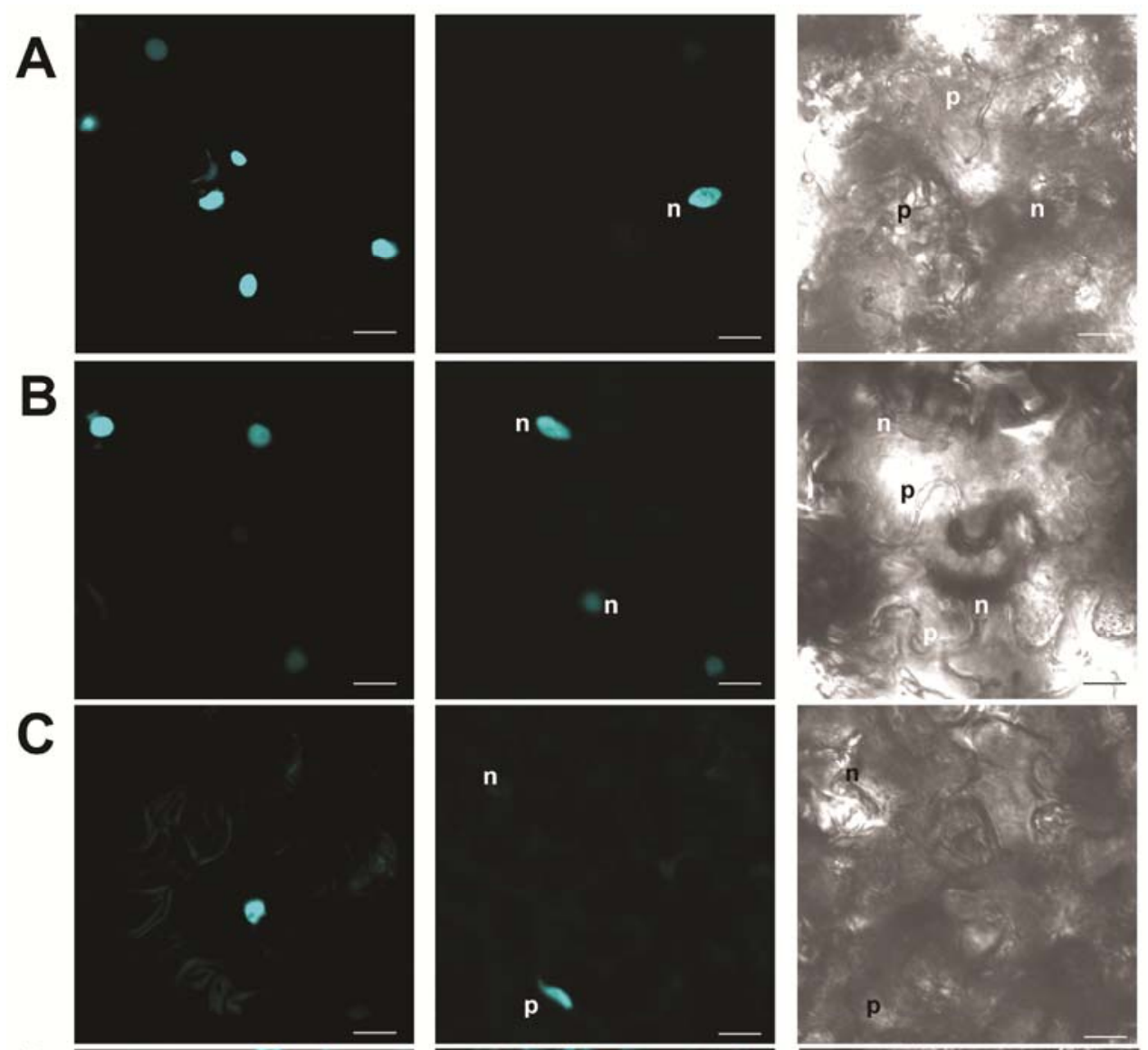

D
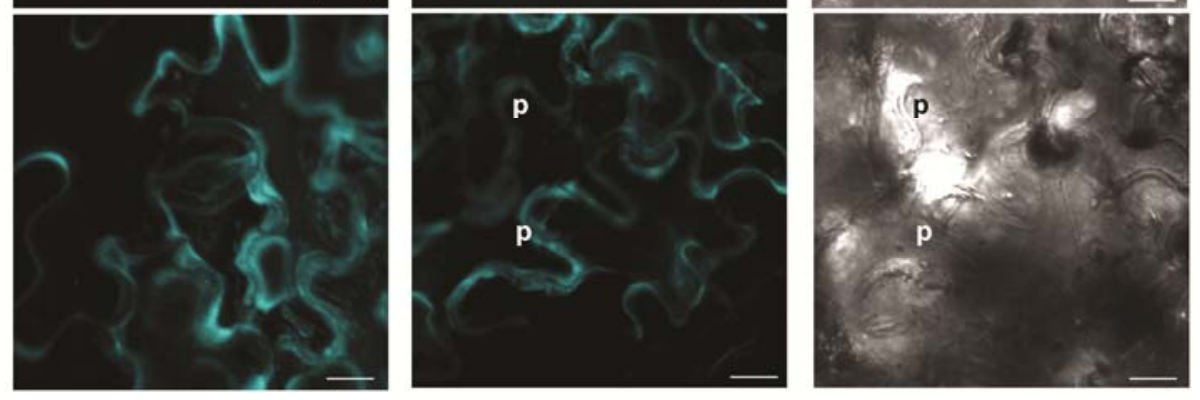

E

\begin{tabular}{|c|c|c|}
\hline A $S P$ & QLLR EER & CFP \\
\hline B $S P$ & AAAA EER & CFP \\
\hline C SP & QLLR AAA & CFP \\
\hline D $\mathbf{S P}$ & AAAA AAA & CFP \\
\hline
\end{tabular}

Fig. 5. A through D, Laser-scanning confocal micrographs showing subcellular localization of transiently expressed CFP-tagged $P c$ QNE_V1 and mutants in Nicotiana benthamiana leaf cells and $\mathbf{E}$, schematic representation of constructs. Images in the left panel are of fluorescence in untreated cells. The center and right panel show the fluorescence and differential interference contrast images of plasmolyzed cells, respectively; $n$, nucleus; $p$, plasma membrane separated from cell wall. Scale bars $=20 \mu \mathrm{m}$. 
based on the sequence of V1, it is not surprising that many other variants can be amplified as well due to their high similarity with each other. Compared with the expression level in isolated sporangia, the expression of $P c Q N E$ genes was induced after infection of plants and reached the highest level at 3 dpi (Fig. 8). This expression pattern is consistent with many functional effectors, which are upregulated upon infection, suggesting a role that $P c \mathrm{QNE}$ plays in facilitating pathogen infection and disease development.

\section{DISCUSSION}

Despite the worldwide economic impact of cucurbit downy mildew, the molecular mechanisms underlying the $P$. cubensis-cucurbit interactions are unknown. The availability of the genome sequences from both pathogens and their hosts has greatly advanced our understanding of pathogen virulence and host resistance (Ebbole 2007; Quirino and Bent 2003). In 2009, Huang and associates (2009) and Ren and associates (2009) presented a genome sequence and cytogenetic blueprint, respectively, for cucumber (Cucumis sativus). However, a lag still exists in developing these resources for the obligate pathogen $P$. cubensis, due in large part to the difficulty in culturing and propagation of the pathogen. For example, the isolation of pure pathogen structures from infected hosts is undoubtedly more challenging than isolation from pure cultures grown on synthetic media. In the present study, we have established the protocols to propagate a pure $P$. cubensis isolate from a single sporangium, to collect highly pure sporangia from infected leaves, and to extract high-quality genomic DNA for 454 pyrosequencing. Although the sequence data we created from this study are still limited, the work presented herein represents the first description of a genomic resource for $P$. cubensis and a glimpse into its pathogenicity mechanisms.

Members of the $P c \mathrm{QNE}$ family possess a functional ERtype signal peptide, and two of the members tested are localized within the host nucleus following secretion and translocation. $P c \mathrm{QNE}$ proteins are under diversifying selection at the C-terminal domains, a common characteristic of oomycetes RXLR effectors (Liu et al. 2005; Oh et al. 2009; Win et al. 2007). They share similar primary sequence structure with a typical RXLR effector protein at the $\mathrm{N}$ terminus, including a signal peptide, Q/RXLR motif, followed by the conserved EER sequence. QXLR and EER are both conserved blocks present in all 47 PcQNE members (Fig. 2), suggesting that QXLR could be a translocation motif, like RXLR. Indeed, internalization of secreted $P c$ QNE_V1 requires the QXLR-EER motif (Fig. 5). Other than RXLR, other translocation motifs, such as LXLFLAK, have been found in the CRINKLER (CRN) family of effectors of Phytophthora spp. and $H$. arabidopsidis (Haas

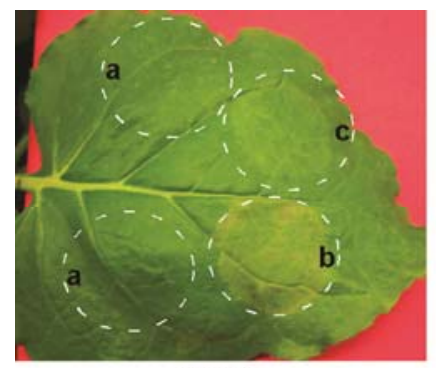

4 dpi

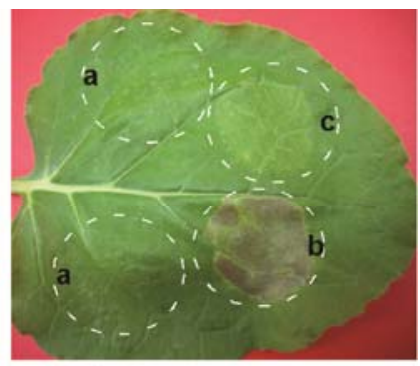

$6 \mathrm{dpi}$
Fig. 6. $P c$ QNE variants induce chlorosis and necrosis in Nicotiana benthamiana. Agrobacterium tumefaciens strains expressing DsRed alone (a), DsRed-V1 (b), or DsRed-V6 (c) were infiltrated into N. benthamiana leaves. Photos were taken at 4 and 6 days postinoculation (dpi). et al. 2009; Win et al. 2007). The identification of additional translocation motifs undoubtedly not only will increase our understanding of the mechanisms of delivery of oomycete effectors but also may shed light into the virulence function of the effectors that do not have a canonical RXLR motif. Moreover, it will increase our awareness of the presence of cytoplasmic effectors other than the RXLR and CRN classes. Indeed, it seems that QXLR-containing secreted proteins are
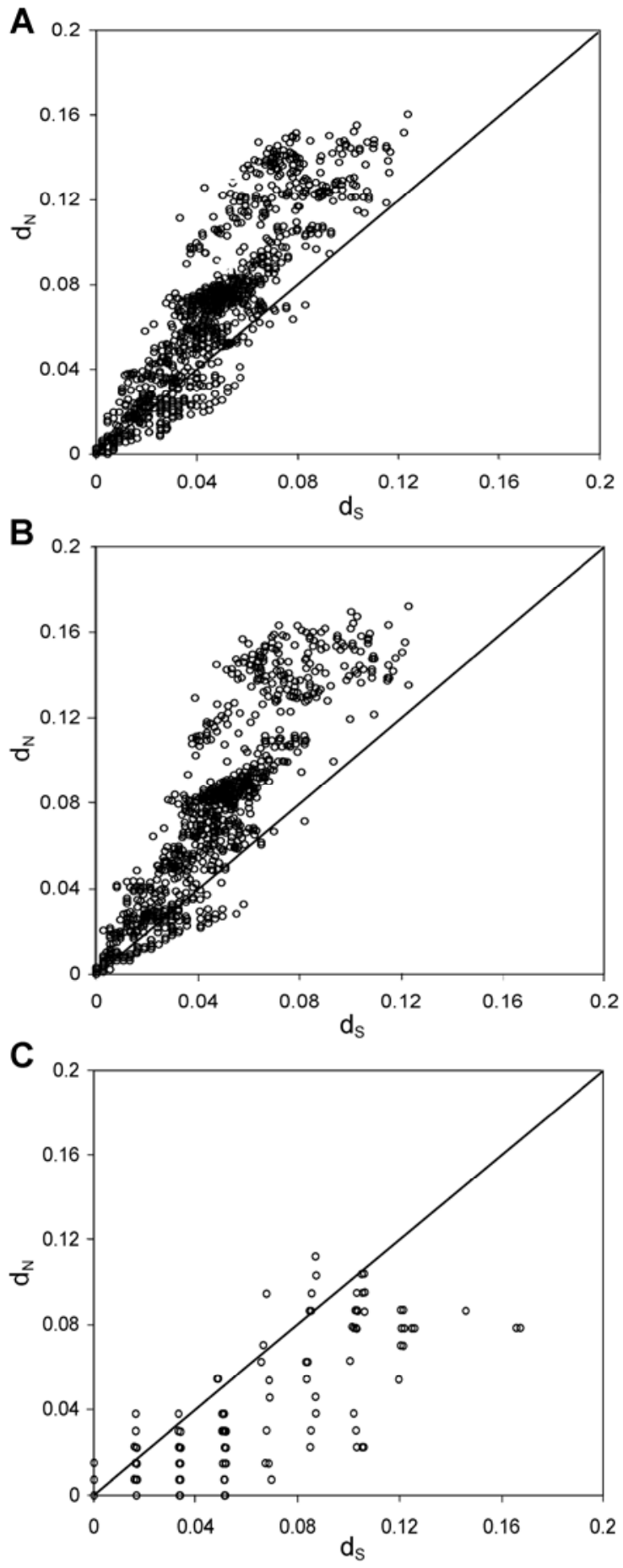

Fig. 7. Rates of nonsynonymous $\left(d_{\mathrm{N}}\right)$ and synonymous $\left(d_{\mathrm{S}}\right)$ nucleotide substitutions of pairwise comparisons with $47 P c \mathrm{QNE}$ sequences. A, Comparison with the entire open reading frame sequences. B, Comparison for the C-terminal regions. $\mathbf{C}$, Comparison for the $\mathrm{N}$-terminal regions. The diagonal line indicates $d_{\mathrm{N}}=d_{\mathrm{S}}$. Points above the line represent comparisons with $\omega=d_{\mathrm{N}} / d_{\mathrm{S}}$ 
fairly common in the $P$. cubensis genome. The identification of members of the $P c$ QNE family as bona fide effectors will certainly help to catalog a comprehensive list of effector proteins of $P$. cubensis.

Although the present study demonstrates that the QXLR motif found in $P$. cubensis is likely a functional translocation motif, previous analyses of the RXLR2 motif of Phytophthora sojae Avrlb showed that substitution of $\mathrm{R}$ to $\mathrm{Q}$ within the RXLR2 motif abolished the translocation of Avr1b to the host soybean cells (Dou et al. 2008; Kale et al. 2010). The simplest explanation for this apparent discrepancy is that differences in the sequences flanking the R/QXLR may alter translocation efficiency. Indeed, the surrounding sequences of RXLR motifs have been shown to be important for translocation (Dou et al. 2008). From a structure-to-function standpoint, one might also argue that mutation of $\mathrm{R}$ to $\mathrm{Q}$ within the RXLR2 motif of Avrlb could influence the native interactions of adjacent amino acids, thus altering protein fold dynamics. By extension, as a result, the mutated protein is unable to be recognized by the translocation machinery. Alternatively, the discrepancy could lie in the specificity of hosts. Recently, Kale and associates (2010) reported that the translocation of cytoplasmic effectors of oomycetes and fungi is a host-mediated process requiring RXLR (or variants)-enabled binding to the phospholipid on the host plasma membrane. Even if QXLR is not readily recognized by the phospholipids of soybean, it could well be functional in cucurbits.

Oomycete effectors often exist in multiple copies within a single genome (Dong et al. 2009; Qutob et al. 2009). For example, the Avrla locus from some strains of P. sojae comprises a tandem array of four near-identical copies (Qutob et al. 2009). Likewise, the $P$. sojae effector $A v r 3 a$ is present in as many as four copies, depending on the strain (Qutob et al. 2009). To determine the extent of duplication of RXLR effector proteins, Qutob and associates (2009) developed a method to estimate the copy number by counting trace file matches from the whole-genome shotgun sequence. Their study suggests that multiple, near-identical copies of RXLR effector genes are prevalent in oomycete genomes. The highest predicted copy number from $P$. sojae and $P$. ramorum is 54 for $P$. sojae Avh426. In the present study, we sequenced $62 P c \mathrm{QNE}$ cDNA clones from a single sporangium-derived Pseudoperonospora cubensis isolate. Among these, there are approximately 42 highly similar yet distinct variants, suggesting that $P c \mathrm{QNE}$ belongs to a large gene family that is likely the target of the evolutionary forces driving the "arms race" between pathogen and host. In this regard, the massive multiplication led us to hypothesize that $P c \mathrm{QNE}$ proteins might play highly important roles in pathogen fitness and pathogenicity.

The biochemical activity of $P c \mathrm{QNE}$ is unclear. $P c \mathrm{QNE}$ proteins do not exhibit any similarity to sequences currently available in the public databases, which is consistent with many identified oomycete effector proteins. An extensive search for domains and motifs against various publicly available databases failed to identify any functional domain. As an attempt to predict, in silico, the biochemical function of $P c$ QNE_V1 by molecular modeling with the I-TASSER server, I-TASSER generated five possible three-dimensional (3-D) structural models (Supplementary Data 7) with a range of confidence scores (C-score). Although we failed to directly identify the biochemical function consistent with the nuclear localization, we used the predicted 3-D structures to address DNA-binding activity through utilization of the DNA Binding Protein Prediction Server. Interestingly, this analysis returned similar results for all five models, suggesting that, in fact, $P c$ QNE proteins are likely DNA-binding proteins. Thus, one can speculate that $P c \mathrm{QNE}$ effectors likely manipulate host cellular processes by altering host gene expression, supporting our finding that $P c$ QNE_V1 is nuclear localized in planta.

Although prediction by Predict NLS did not identify a putative NLS in PcQNE_V1 protein sequence, this protein was experimentally determined to be localized in the nucleus. However, this apparent discrepancy is not contradictory. The database used for prediction is composed of experimentally known NLS and potential NLS generated through in silico mutagenesis (Cokol et al. 2000), and the list of NLS in the database is by no means complete. Thus, failure to identify a canonical NLS in a protein does not necessarily imply that there is not a functional NLS present. To this end, PcQNE_V1 could be such an example of a protein with a novel, uncharacterized NLS. In support of this, a stretch of sequence (KRKRPEGTEIQFRWKESEIINLYTKHM) in PcQNE_V1, which aligns very well with the putative NLS of $P c$ QNE_V6, with 4 amino acids divergent from PcQNE_V6 (Fig. 2.), may represent a novel NLS absent in the Predict NLS database.

In total, the work presented herein represents the characterization of a family of secreted effector proteins from the cucurbit downy mildew pathogen $P$. cubensis. As a reference tool for further analyses of oomycete effector motifs, our data supports the idea that $P$. cubensis, compared with other agriculturally important oomycetes such as Phytophthora sojae and $P$. infestans, may utilize alternative translocation motifs (i.e., QXLR) in addition to the well-established RXLR. This study provides evidence supporting the need for the further characterization of additional translocation motifs from plant pathogens.

\section{MATERIALS AND METHODS}

Plants used and growth conditions.

Cucumber (C. sativus) 'Vlaspik' was used throughout the study and grown in a growth chamber with cycles of $25^{\circ} \mathrm{C}$ in light for $14 \mathrm{~h}$ and $20^{\circ} \mathrm{C}$ in darkness for $10 \mathrm{~h}$. N. benthamiana plants were grown at $20^{\circ} \mathrm{C}$ under a cycle of $14 \mathrm{~h}$ of light and $10 \mathrm{~h}$ of darkness.

\section{Pathogen isolation, inoculation, and maintenance.}

The Pseudoperonospora cubensis isolate used in this study was collected from infected cucumber leaves grown in Homerville, $\mathrm{OH}$ in 2007. Diseased leaves were incubated overnight in a moist container and washed with sterile water to collect sporan-

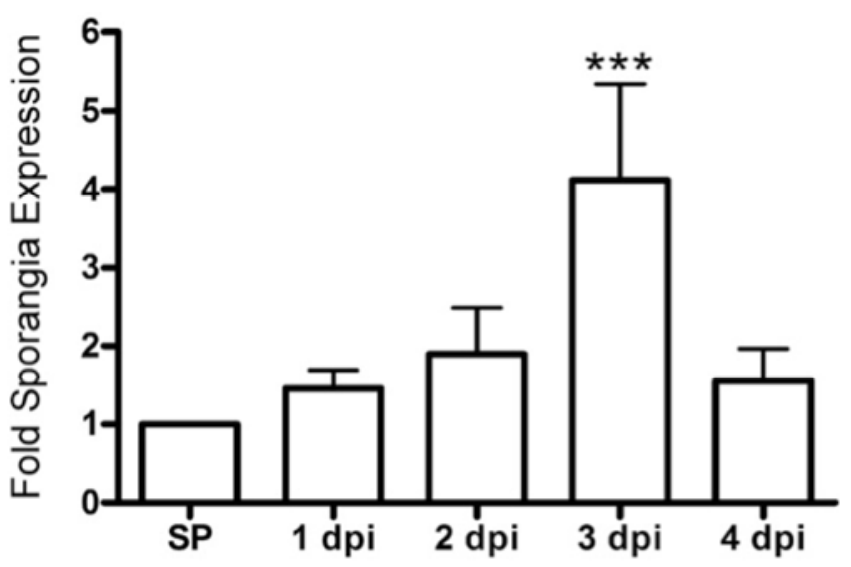

Fig. 8. Expression levels of $P c Q N E$ in sporangia (SP) and at 1, 2, 3 and 4 days postinoculation (dpi). Expression is displayed as fold sporangia expression. Error bars represent the standard error of the mean of two technical replicates from each of two biological replicates; $* * *$ indicates statistical significance compared with sporangia control $(P<0.001)$ using two-way analysis of variance. 
gia. Single sporangia were isolated by spreading the sporangia suspension on $1.5 \%$ water agar and cutting the agar into small pieces. The small pieces with single sporangia, observed under a microscope, were placed onto the detached cucumber leaf discs or whole leaves in a moist container for infection. At 5 to $7 \mathrm{dpi}$, propagated sporangia from the single sporangia-infected leaf tissues were collected. Subsequent pathogen propagation and maintenance were carried out by spraying a sporangia suspension $\left(10^{4}\right.$ sporangia/ml $)$ on the leaves of intact plants. Inoculated plants were kept in a plastic tray with lids covered to maintain approximately $100 \%$ humidity, kept in darkness at ambient temperature for $24 \mathrm{~h}$, and then moved to the growth chamber with the same settings for growing healthy cucumber plants described above. For examining the expression of PcQNE during the infection time course, 4-week-old plants were drop inoculated on the abaxial surface with $10 \mu \mathrm{l}$ of a $1 \times 10^{5}$ sporangia/ml solution and then treated as described for spray inoculation.

\section{Collection and purification of sporangia and isolation of genomic DNA and total RNA.}

Sporangia were detached from infected leaves by submerging the leaves in sterile water and gently swirling for $5 \mathrm{~min}$. Sporangia suspension was passed through eight layers of cheesecloth followed by passage through a $45-\mu$ m nylon mesh. Sporangia were then collected by centrifugation at $1,000 \times g$ for $5 \mathrm{~min}$. The purity of sporangia was checked using light microscopy. Once a sample was confirmed as having a minimal amount (i.e., $<2 \%$ ) of plant tissue contamination, sporangia were processed for genomic DNA and total RNA isolation. DNA and RNA isolation from sporangia were performed with the DNeasy plant mini kit and RNeasy plant mini kit (Qiagen), respectively. Briefly, sporangia were resuspended in $400 \mu \mathrm{l}$ of buffer AP1 (for DNA extraction) or RLT (for RNA isolation) and then and equal volume of 525-to $600-\mu \mathrm{m}$ acid-washed glass beads (Sigma) was added. Suspended sporangia were disrupted by vigorously shaking for 12 s using a FastPrep FP120 beadbeater (ThermoSavant). DNA and RNA isolations were performed following the manufacturer's instructions.

\section{4 sequencing and assembly.}

Sequencing of $P$. cubensis genomic DNA isolated from sporangia was performed using the 454 GS-FLX Titanium Sequencer (Roche) at the Michigan State University Research Technology Support Facility. The procedure was described previously (Quinn et al. 2008). The reads were screened for contaminated cucumber DNA using the available sequence data from the NCBI databases. After the identifiable cucumber sequences were removed, the remaining reads were assembled using the Roche gsAssembler (version 1.1.03).

\section{Sequence analyses to identify putative RXLR and QXLR effector proteins.}

Putative RXLR effector proteins were identified using the RXLR effector identification pipeline and the HMMsearch program using an HMM profile constructed based on 43 validated oomycete RXLR effectors, as described previously (Win et al. 2007). Putative QXLR effector proteins were identified using a modified pipeline from the RXLR effector identification pipeline. In brief, the search string in the PERL script was changed from RXLR to QXLR to modify the search for QXLR-containing secreted proteins.

\section{Validation of the functionality of $P c Q N E$ signal peptides.}

The functionality of predicted $P c$ QNE signal peptides was validated using the yeast secretion system described by Jacobs and associates (1997). In brief, SP1 and SP2 were fused to the invertase gene SUC2 lacking both its initiating methionine codon and its signal peptide, by cloning the PCR-amplified fragments into the EcoRI and XhoI sites of the yeast signal sequence trap vector pSUC2T7M13ORI. The same forward primer $\left(5^{\prime}-\right.$ GCGGAATTCatgatgcccctgcgaaactcg-3') was used for amplifying both signal peptides. The reverse primers $5^{\prime}$-GCGCTCGA Gcgctagaacgatagacgaagca-3' and 5'-GCGCTCGAGcgctcagatct cgctagaacga-3' were used for SP1 and SP2, respectively (genespecific sequence is in lowercase and the introduced restriction sites are underlined). The plasmid constructs, named pSUC2SP1 and pSUC2-SP2, together with the original vector, were transferred into the yeast SUC2-minus strain YTK12 using the Frozen-EZ Yeast Transformation IITM kit (Zymo Research, Orange, CA, U.S.A.) following the manufacturer's instructions. Transformants were selected by growing on CMD-W plates $(0.67 \%$ yeast nitrogen base without amino acids, $0.075 \%$ tryptophan dropout supplement, $2 \%$ sucrose, $0.1 \%$ glucose, and $2 \%$ agar) for 3 days. To test whether SP1 and SP2 were functional by yeast growth assays, single colonies of YTK12 with or without expressing various plasmids were streaked onto raffinosecontaining YPRAA plates (1\% yeast extract, $2 \%$ peptone, $2 \%$ raffinose, Antimycin A at $2 \mu \mathrm{g} /$ liter, and $2 \%$ agar) (Jacobs et al. 1997). Yeast strains were replicated onto YPDA plates $(1 \%$ yeast, $2 \%$ peptone, $2 \%$ glucose, $0.003 \%$ adenine hemisulfate, and $2 \%$ agar) and CMD-W plates as equal viability controls. The detection of the secreted invertase activity with TTC was performed as described by Oh and associates (2009).

\section{3' RACE-PCR, RT-PCR, DNA sequencing, and sequence analyses.}

Total RNA isolated from $P$. cubensis sporangia was treated with DNA-Free (Ambion, Austin, TX, U.S.A.) to remove residual genomic DNA. Synthesis of 3'-RACE-Ready cDNA and 3' RACE-PCR were performed with total RNA using the Smart RACE cDNA amplification kit (Clontech, Mountain View, CA, U.S.A.) following the instructions of the manufacturer. A genespecific primer was designed based on the partial sequence obtained from 454 sequencing. The resultant RACE-PCR product was cloned into the PCR2.1 TOPO vector (Invitrogen, San Diego, CA, U.S.A.) and sequenced with an ABI 3730 Genetic Analyzer. For amplification of $P c \mathrm{QNE}$ cDNA sequences encoding the ORF, 3'-RACE-Ready cDNA was used as template. PCR with gene-specific primers (forward, $5^{\prime}$-atgatgcccctgcgaaactcg$3^{\prime}$; reverse, $5^{\prime}$-tcatgtggagacggcaggagttc- $3^{\prime}$ ) was carried out for 35 cycles using $P f u$ Turbo DNA polymerase (Stratagene. La Jolla, CA, U.S.A.). The amplicons were cloned and sequenced as described above. Sequences were aligned and checked against chromatograms using Sequencher 4.7 (Gene Codes, Ann Arbor, MI, U.S.A.). Signal peptides were predicted by SignalP 3.0. Putative NLS were identified by PredictNLS. Multiple alignments were generated with ClustalX version 1.8.

\section{Transient expression}

in $N$. benthamiana and subcellular localization.

The plasmids for expressing mature proteins of $P c \mathrm{QNE} \_\mathrm{V} 1$ and PcQNE_V6 fused with DsRed at the N-terminus were constructed by cloning PCR-amplified fragments encoding V1 and V6 mature proteins into BglII and HindIII sites of pGDR (Goodin et al. 2002). The two primers used were forward: 5'-gcgagatctAGATATGAGGCGTCTACTGATATC-3' and reverse: 5'-gcgaagcttTCATGTGGAGACGGCAGGAGTTC-3' (the gene-specific sequence is in uppercase and the introduced restriction sites are underlined). For observing internalization of secreted PcQNE_V1 and its mutants with QXLR or EER substituted for alanine (A), C-terminal CFP fusion expression constructs were made as follows. Full-length V1 was first cloned into the Gateway entry vector $\mathrm{pENTR/D-TOPO} \mathrm{(Invitrogen)}$ using gene-specific primers (forward: 5'-caccATGATGCCCC 
CTGCGAA-3' and reverse: 5'-TGTGGAGACGGCAGGAGT TC-3') to make PcQNE_V1_GW. To make V1 mutants, sitedirected mutagenesis was done via quick-change PCR using PcQNE_V1_GW as a template. The change from QLLR to AAAA to generate PcQNE_V1_AAAA_GW was done in two steps: i) the QLLR motif was altered to ALAR using the primers forward: 5'-GACACGAAGGCACTCGCGCGGACTTCTG AC-3' and reverse: 5'-GTCAGAAGTCCGCGCGAGTGCCTT CGTGTC-3') and ii) the ALAR was further altered to AAAA using the primers forward: 5'-GACACGAAGGCAGCCGCGG CGACTTCTGAC-3' and reverse: 5'-GTCAGAAGTCGCCGC GGCTGCCTTCGTGTC-3'. To change the EER motif to AAA generating $P c$ QNE_V1_AAA, the primer set forward: 5'-AA GGATAACGCAGCGGCGATGTTCAAC-3' and reverse: 5'GTTGAACATCGCC $\underline{G C T G C G T T A T C C T T-3^{\prime}}$ was used. To make the mutant with both the QLLR and EER motifs converted to alanines, the PcQNE_V1_AAAA_GW construct was used as a template for site-directed mutagenesis with the primers described to change the EER motif to AAA. For all primers, the underlined bases indicate mutations. Quick-change PCR was performed for 18 cycles $\left(95^{\circ} \mathrm{C}, 1 \mathrm{~min} ; 55^{\circ} \mathrm{C}, 3 \mathrm{~min}\right.$; and $68^{\circ} \mathrm{C}, 5 \mathrm{~min}$ ) on a BioRad MyCycler thermal cycler (BioRad Laboratories, Hercules, CA, U.S.A.) using Pfu Turbo DNA polymerase (Clontech). Resultant products were treated with DpnI overnight at $37^{\circ} \mathrm{C}$ and then transformed into Escherichia coli $\mathrm{DH} 5 \alpha$ cells. Clones were sequenced to verify mutagenesis. C-terminal CFP fusion expression constructs were further generated from the above entry clones to the destination vector pVKH18En6gw-cCFP using recombination via LR Clonase per the manufacturer's instructions (Invitrogen).

Construction of the pVKH18En6gw-cCFP vector was performed as follows. The Gateway Reading Frame Cassette was amplified using $P f u$ Ultra II HS fusion (Stratagene) with a forward primer that introduced a unique $X b a I$ site and a reverse primer that introduced a unique XhoI site. The amplified product was verified by agarose gel electrophoresis and purified using a MicroSpin S-400 HR column (GE Healthcare, Piscataway, NJ, U.S.A.). The purified product was digested with $\mathrm{XbaI}$ and XhoI and ligated into an XbaI- and SalI-restricted pVKH18En6 binary plasmid containing the Cerulean CFP gene (Batoko et al. 2000; Rizzo et al. 2004).

For transient expression in $N$. benthamiana, the expression constructs described above were transformed into A. tumefaciens C58-C1. Confocal microscopy was performed as described previously (Goodin et al. 2002; Tian et al. 2009) using the Olympus FluoView. For plasmolysis analysis, cells were treated using $0.8 \mathrm{M}$ mannitol for 10 to $15 \mathrm{~min}$ prior to imaging (Rafiqi et al. 2010).

\section{Diversifying selection analyses.}

Diversifying selection analyses were performed as described by $\mathrm{Oh}$ and associates (2009). The rates of nonsynonymous nucleotide substitutions per site $\left(d_{\mathrm{N}}\right)$ and the rates of synonymous nucleotide substitutions per site $\left(d_{\mathrm{S}}\right)$ in all pairwise comparisons were estimated using the approximate methods of Yang and Nielsen (2000) and Nei and Gojobori (1986) implemented in the YN00 program in the PAML4.2a software package (Yang 2007).

\section{Quantitative RT-PCR.}

Total RNA was extracted from $P$. cubensis-infected cucumber leaves at 1, 2, 3, and 4 dpi using the PrepEase plant RNA spin kit (USB, Cleveland, OH, U.S.A.) per the manufacturer's instructions. First-strand cDNA was synthesized from $1 \mu \mathrm{g}$ total RNA using the First-strand cDNA synthesis kit (USB). Quantitative RT-PCR was performed on a Mastercycler ep Realplex real-time PCR (Eppendorf, Hamburg, Germany) using HotStart
SYBR Green qPCR Master Mix (2×) (USB). For amplification of PcQNE transcripts, gene-specific forward (5'-TCCGACAT GACACGAACGAACTCT-3') and reverse (5'-AGTGAGACA TCGTAGATGCGCGTT-3') primers were used. Primers specific for the $P$. cubensis internal transcribed spacer region (forward: 5'-CGGGGGTTTTGTTTGGCGGT-3' and reverse: 5'CGAAGCCCAAACGCTCGCCA-3') were used as an endogenous control. Cycle time used was $95^{\circ} \mathrm{C}$ for $2 \mathrm{~min}$ followed by 40 cycles of $95^{\circ} \mathrm{C}$ for $15 \mathrm{~s}, 60^{\circ} \mathrm{C}$ for $15 \mathrm{~s}$, and $72^{\circ} \mathrm{C}$ for $45 \mathrm{~s}$. Fold expression was calculated based on expression in sporangia and data were analyzed by two-way analysis of variance using Prism 4 (GraphPad Software, La Jolla, CA, U.S.A.).

\section{ACKNOWLEDGMENTS}

We thank B. Cortright and M. Hausbeck of Michigan State University for providing P. cubensis-infected cucumber leaves, and L. Cano of The Sainsbury Laboratory for technical advice on the yeast invertase secretion assay. This research was supported by grants from project GREEEN (Michigan State University; GR07-077), funds from the Pickle Packers Agriculture Research Fund and, in part, by a National Science Foundation CAREER Award (IOS-0641319) to B. Day. The support of the Michigan Agricultural Experiment Station is also acknowledged. J. Win was supported by the Gatsby Charitable Foundation.

\section{LITERATURE CITED}

Alfano, J. R., and Collmer, A. 2004. Type III secretion system effector proteins: Double agents in bacterial disease and plant defense. Annu. Rev. Phytopathol. 42:385-414.

Armstrong, M. R., Whisson, S. C., Pritchard, L., Bos, J. I., Venter, E., Avrova, A. O., Rehmany, A. P., Bohme, U., Brooks, K., Cherevach, I., Hamlin, N., White, B., Fraser, A., Lord, A., Quail, M. A., Churcher, C., Hall, N., Berriman, M., Huang, S., Kamoun, S., Beynon, J. L., and Birch, P. R. 2005. An ancestral oomycete locus contains late blight avirulence gene Avr3a, encoding a protein that is recognized in the host cytoplasm. Proc. Natl. Acad. Sci. U.S.A. 102:7766-7771.

Arnold, R., Brandmaier, S., Kleine, F., Tischler, P., Heinz, E., Behrens, S., Niinikoski, A., Mewes, H. W., Horn, M., and Rattei, T. 2009. Sequencebased prediction of type III secreted proteins. PLoS Pathog. 5:e1000376. Published online.

Batoko, H., Zheng, H.Q., Hawes, C., and Moore, I. 2000. A rab1 GTPase is required for transport between the endoplasmic reticulum and Golgi apparatus and for normal Golgi movement in plants. Plant Cell 12:2201-2218.

Bhattacharjee, S., Hiller, N. L., Liolios, K., Win, J., Kanneganti, T. D., Young, C., Kamoun, S., and Haldar, K. 2006. The malarial host-targeting signal is conserved in the Irish potato famine pathogen. PLoS Pathog. 2:e50. Published online.

Birch, P. R., Boevink, P. C., Gilroy, E. M., Hein, I., Pritchard, L., and Whisson, S. C. 2008. Oomycete RXLR effectors: Delivery, functional redundancy and durable disease resistance. Curr. Opin. Plant Biol. 11:373-379.

Birch, P. R., Armstrong, M., Bos, J., Boevink, P., Gilroy, E. M., Taylor, R. M., Wawra, S., Pritchard, L., Conti, L., Ewan, R., Whisson, S. C., van West, P., Sadanandom, A., and Kamoun, S. 2009. Towards understanding the virulence functions of RXLR effectors of the oomycete plant pathogen Phytophthora infestans. J. Exp. Bot. 60:1133-1140.

Buttner, D., and He, S. Y. 2009. Type III Protein secretion in plant pathogenic bacteria. Plant Physiol. 150:1656-1664.

Chisholm, S. T., Coaker, G., Day, B., and Staskawicz, B. J. 2006. Hostmicrobe interactions: Shaping the evolution of the plant immune response. Cell 124:803-814.

Cline, J., Braman, J. C., and Hogrefe, H. H. 1996. PCR fidelity of $p f u$ DNA polymerase and other thermostable DNA polymerases. Nucleic Acids Res. 24:3546-3551.

Cokol, M., Nair, R., and Rost, B. 2000. Finding nuclear localization signals. EMBO (Eur. Mol. Biol. Organ.) Rep. 1:411-415.

Davis, E. L., Hussey, R. S., Mitchum, M. G., and Baum, T. J. 2008. Parasitism proteins in nematode-plant interactions. Curr. Opin. Plant Biol. 11:360-366.

Dodds, P. N., Rafiqi, M., Gan, P. H., Hardham, A. R., Jones, D. A., and Ellis, J. G. 2009. Effectors of biotrophic fungi and oomycetes: Pathogenicity factors and triggers of host resistance. New Phytol. 183:993-1000.

Dong, S., Qutob, D., Tedman-Jones, J., Kuflu, K., Wang, Y., Tyler, B. M., and Gijzen, M. 2009. The Phytophthora sojae avirulence locus Avr3c 
encodes a multi-copy RXLR effector with sequence polymorphisms among pathogen strains. PLoS One 4:e5556. Published online.

Dou, D., Kale, S. D., Wang, X., Jiang, R. H., Bruce, N. A., Arredondo, F D., Zhang, X., and Tyler, B. M. 2008. RXLR-mediated entry of Phytophthora sojae effector Avr1b into soybean cells does not require pathogen-encoded machinery. Plant Cell 20:1930-1947.

Ebbole, D. J. 2007. Magnaporthe as a model for understanding hostpathogen interactions. Annu. Rev. Phytopathol. 45:437-456.

Goodin, M. M., Dietzgen, R. G., Schichnes, D., Ruzin, S., and Jackson, A O. 2002. pGD vectors: Versatile tools for the expression of green and red fluorescent protein fusions in agroinfiltrated plant leaves. Plant J. $31: 375-383$

Grouffaud, S., van West, P., Avrova, A. O., Birch, P. R., and Whisson, S. C. 2008. Plasmodium falciparum and Hyaloperonospora parasitica effector translocation motifs are functional in Phytophthora infestans. Microbiology 154:3743-3751.

Haas, B. J., Kamoun, S., Zody, M. C., Jiang, R. H., Handsaker, R. E., Cano, L. M., Grabherr, M., Kodira, C. D., Raffaele, S., Torto-Alalibo, T., Bozkurt, T. O., Ah-Fong, A. M., Alvarado, L., Anderson, V. L., Armstrong, M.R., Avrova, A., Baxter, L., Beynon, J., Boevink, P. C., Bollmann, S. R., Bos, J. I., Bulone, V., Cai, G., Cakir, C., Carrington, J. C., Chawner, M., Conti, L., Costanzo, S., Ewan, R., Fahlgren, N., Fischbach, M. A., Fugelstad, J., Gilroy, E. M., Gnerre, S., Green, P. J., Grenville-Briggs, L. J., Griffith, J., Grünwald, N. J., Horn, K., Horner, N. R., Hu, C. H., Huitema, E., Jeong, D. H., Jones, A. M., Jones, J. D., Jones, R. W., Karlsson, E. K., Kunjeti, S. G., Lamour, K., Liu, Z., Ma, L., Maclean, D., Chibucos, M. C., McDonald, H., McWalters, J., Meijer, H. J., Morgan, W., Morris, P. F., Munro, C. A., O’Neill, K., Ospina-Giraldo, M., Pinzón, A., Pritchard, L., Ramsahoye, B., Ren, Q., Restrepo, S., Roy, S., Sadanandom, A., Savidor, A., Schornack, S., Schwartz, D. .C., Schumann, U. D., Schwessinger, B., Seyer, L., Sharpe, T., Silvar, C., Song, J., Studholme, D. J., Sykes, S., Thines, M., van de Vondervoort, P. J., Phuntumart, V., Wawra, S., Weide, R., Win, J., Young, C., Zhou, S., Fry, W., Meyers, B. C., van West, P., Ristaino, J., Govers, F., Birch, P. R., Whisson, S. C., Judelson, H. S., and Nusbaum, C.. 2009. Genome sequence and analysis of the Irish potato famine pathogen Phytophthora infestans. Nature 461:393-398.

Hogenhout, S. A., Van der Hoorn, R. A., Terauchi, R., and Kamoun, S. 2009. Emerging concepts in effector biology of plant-associated organisms. Mol. Plant-Microbe Interact. 22:115-122.

Holmes, G., Wehner, T., and Thornton, A. 2006. An old enemy re-emerges. Am. Veg. Grow. February:14-15

Huang, S., Li, R., Zhang, Z., Li, L., Gu, X., Fan, W., Lucas, W. J., Wang, X., Xie, B., Ni, P., Ren, Y., Zhu, H., Li, J., Lin, K., Jin, W., Fei, Z., Li, G., Staub, J., Kilian, A., van der Vossen, E. A., Wu, Y., Guo, J., He, J., Jia, Z., Ren, Y., Tian, G., Lu, Y., Ruan, J., Qian, W., Wang, M., Huang, Q., Li, B., Xuan, Z., Cao, J., Asan, Wu, Z., Zhang, J., Cai, Q., Bai, Y., Zhao, B., Han, Y., Li, Y., Li, X., Wang, S., Shi, Q., Liu, S., Cho, W. K., Kim, J. Y., Xu, Y., Heller-Uszynska, K., Miao, H., Cheng, Z., Zhang, S., Wu, J., Yang, Y., Kang, H., Li, M., Liang, H., Ren, X., Shi, Z., Wen, M., Jian, M., Yang, H., Zhang, G., Yang, Z., Chen, R., Liu, S., Li, J., Ma, L., Liu, H., Zhou, Y., Zhao, J., Fang, X., Li, G., Fang, L., Li, Y., Liu, D., Zheng, H., Zhang, Y., Qin, N., Li, Z., Yang, G., Yang, S., Bolund, L., Kristiansen, K., Zheng, H., Li, S., Zhang, X., Yang, H., Wang, J., Sun, R., Zhang, B., Jiang, S., Wang, J., Du, Y., and Li, S. 2009. The genome of the cucumber, Cucumis sativus L. Nat. Genet. 41:1275-1281.

Jacobs, K. A., Collins-Racie, L. A., Colbert, M., Duckett, M., Golden-Fleet, M., Kelleher, K., Kriz, R., LaVallie, E. R., Merberg, D., Spaulding, V., Stover, J., Williamson, M. J., and McCoy, J. M. 1997. A genetic selection for isolating cDNAs encoding secreted proteins. Gene 198:289-296.

Jiang, R. H., Tripathy, S., Govers, F., and Tyler, B. M. 2008. RXLR effector reservoir in two Phytophthora species is dominated by a single rapidly evolving superfamily with more than 700 members. Proc. Natl. Acad. Sci. U.S.A. 105:4874-4879.

Jones, J. D., and Dangl, J. L. 2006. The plant immune system. Nature 444:323-329

Kale, S. D., Gu, B., Capelluto, D. G., Dou, D., Feldman, E., Rumore, A., Arredondo, F. D., Hanlon, R., Fudal, I., Rouxel, T., Lawrence, C. B., Shan, W., and Tyler, B. M. 2010. External lipid PI3P mediates entry of eukaryotic pathogen effectors into plant and animal host cells. Cell 142:284-295

Kamoun, S. 2006. A catalogue of the effector secretome of plant pathogenic oomycetes. Annu. Rev. Phytopathol. 44:41-60.

Liu, Z., Bos, J. I., Armstrong, M., Whisson, S. C., da Cunha, L., TortoAlalibo, T., Win, J., Avrova, A. O., Wright, F., Birch, P. R., and Kamoun, S. 2005. Patterns of diversifying selection in the phytotoxin-like scr74 gene family of Phytophthora infestans. Mol. Biol. Evol. 22:659-672.

Morgan, W., and Kamoun, S. 2007. RXLR effectors of plant pathogenic oomycetes. Curr. Opin. Microbiol. 10:332-338.
Nei, M., and Gojobori, T. 1986. Simple methods for estimating the numbers of synonymous and nonsynonymous nucleotide substitutions. Mol Biol. Evol. 3:418-426.

Oh, S. K., Young, C., Lee, M., Oliva, R., Bozkurt, T. O., Cano, L. M., Win, J., Bos, J. I., Liu, H. Y., van Damme, M., Morgan, W., Choi, D., Van der Vossen, E. A., Vleeshouwers, V. G., and Kamoun, S. 2009. In planta expression screens of Phytophthora infestans RXLR effectors reveal diverse phenotypes, including activation of the Solanum bulbocastanum disease resistance protein Rpi-blb2. Plant Cell 21:2928-2947.

Quinn, N. L., Levenkova, N., Chow, W., Bouffard, P., Boroevich, K. A., Knight, J. R., Jarvie, T. P., Lubieniecki, K. P., Desany, B. A., Koop, B. F., Harkins, T. T., and Davidson, W. S. 2008. Assessing the feasibility of GS FLX Pyrosequencing for sequencing the Atlantic salmon genome. BMC Genomics 9:404.

Quirino, B. F., and Bent, A. F. 2003. Deciphering host resistance and pathogen virulence: The Arabidopsis/Pseudomonas interaction as a model. Mol. Plant Pathol. 4:517-530.

Qutob, D., Tedman-Jones, J., Dong, S., Kuflu, K., Pham, H., Wang, Y., Dou, D., Kale, S. D., Arredondo, F. D., Tyler, B. M., and Gijzen, M. 2009. Copy number variation and transcriptional polymorphisms of Phytophthora sojae RXLR effector genes Avr1a and Avr3a. PLoS One 4:e5066. Published online.

Rafiqi, M., Gan, P. H., Ravensdale, M., Lawrence, G. J., Ellis, J. G., Jones, D. A., Hardham, A. R., and Dodds, P. N. 2010. Internalization of flax rust avirulence proteins into flax and tobacco cells can occur in the absence of the pathogen. Plant Cell 22:2017-2032.

Rehmany, A. P., Gordon, A., Rose, L. E., Allen, R. L., Armstrong, M. R., Whisson, S. C., Kamoun, S., Tyler, B. M., Birch, P. R., and Beynon, J. L. 2005. Differential recognition of highly divergent downy mildew avirulence gene alleles by RPP1 resistance genes from two Arabidopsis lines. Plant Cell 17:1839-1850.

Ren, Y., Zhang, Z., Liu, J., Staub, J. E., Han, Y., Cheng, Z., Li, X., Lu, J., Miao, H., Kang, H., Xie, B., Gu, X., Wang, X., Du, Y., Jin, W., and Huang, S. 2009. An integrated genetic and cytogenetic map of the cucumber genome. PLoS One 4:e5795. Published online.

Rizzo M. A., Springer, G. H., Granada, B., and Piston, D. 2004. An improved cyan fluorescent protein variant useful for FRET. Nat. Biotechnol. 22:445-449.

Samudrala, R., Heffron, F., and McDermott, J. E. 2009. Accurate prediction of secreted substrates and identification of a conserved putative secretion signal for type III secretion systems. PLoS Pathog. 5:e1000375. Published online.

Savory, E. A., Granke, L. L., Quesada-Ocampo, L. M., Varbanova, M., Hausbeck, M., and Day, B. 2010. The cucurbit downy mildew pathogen Pseudoperonospora cubensis. Mol. Plant Pathol. 12:217-226.

Shan, W., Cao, M., Leung, D., and Tyler, B. M. 2004. The Avr1b locus of Phytophthora sojae encodes an elicitor and a regulator required for avirulence on soybean plants carrying resistance gene Rps1b. Mol. Plant-Microbe Interact. 17:394-403.

Tian, M., Chaudhry, F., Ruzicka, D. R., Meagher, R. B., Staiger, C. J., and Day, B. 2009. Arabidopsis actin-depolymerizing factor AtADF4 mediates defense signal transduction triggered by the Pseudomonas syringae effector AvrPphB. Plant Physiol. 150:815-824.

Voglmayr, H., and Greilhuber, J. 1998. Genome size determination in peronosporales (Oomycota) by Feulgen image analysis. Fungal Genet. Biol. 25:181-195.

Whisson, S. C., Boevink, P. C., Moleleki, L., Avrova, A. O., Morales, J. G., Gilroy, E. M., Armstrong, M. R., Grouffaud, S., van West, P., Chapman, S., Hein, I., Toth, I. K., Pritchard, L., and Birch, P. R. 2007. A translocation signal for delivery of oomycete effector proteins into host plant cells. Nature 450:115-118.

Win, J., Morgan, W., Bos, J., Krasileva, K. V., Cano, L. M., ChaparroGarcia, A., Ammar, R., Staskawicz, B. J., and Kamoun, S. 2007. Adaptive evolution has targeted the C-terminal domain of the RXLR effectors of plant pathogenic oomycetes. Plant Cell 19:2349-2369.

Yang, Z. 2007. PAML 4: Phylogenetic analysis by maximum likelihood. Mol. Biol. Evol. 24:1586-1591.

Yang, Z., and Nielsen, R. 2000. Estimating synonymous and nonsynonymous substitution rates under realistic evolutionary models. Mol. Biol. Evol. 17:32-43.

\section{AUTHOR-RECOMMENDED INTERNET RESOURCES}

PredictProtein database: www.predictprotein.org

SignalP 3.0 server: www.cbs.dtu.dk/services/SignalP

I-TASSER server: zhanglab.ccmb.med.umich.edu/I-TASSER

DNA-binding protein prediction server:

www.enzim.hu/ szia/dnabind.htm 